\title{
The French Society of Internal Medicine's Top-5 List of Recommendations: a National Web-Based Survey
}

\author{
Nathan Peiffer-Smadja, MD, $\mathrm{MS}^{1,2}$, Adeline Bauvois, $\mathrm{MD}^{1,2}$, Marie Chilles, $\mathrm{MD}^{7}$, \\ Baptiste Gramont, $\mathrm{MD}^{7}$, Redwan Maatoug, $\mathrm{MD}^{7}$, Marie Bismut, $\mathrm{MD}^{7}$, \\ Camille Thorey, $M D^{7}$, Eric Oziol, $M D^{3}$, and Thomas Hanslik, MD, PhD ${ }^{3}$
}

'Junior Internist Association, Amicale des Jeunes Internistes (AJI), Paris, France; ${ }^{2}$ Assistance Publique - Hôpitaux de Paris, Hôpital Bichat-Claude Bernard, Paris, France; ${ }^{3}$ French National Society of Internal Medicine, Société Nationale Française de Médecine Interne (SNFMI), Paris, France.

BACKGROUND: The international project "Choosing Wisely" aims to target unnecessary and potentially harmful examinations and treatments.

OBJECTIVE: To define the French Internal Medicine Top-5 list.

DESIGN: Based on a review of existing Top-5 lists and personal experience, a working group of the French National Society of Internal Medicine selected 27 diagnostic and therapeutic procedures. They were submitted through a national web-based survey to French internists who rated from 1 to 5 the perceived frequency, uselessness, and risk of each procedure. A composite score was calculated as the unweighted addition of the three scores. PARTICIPANTS: Four hundred thirty internists answered the web-based survey (14\% of all French internists including residents). All the French regions and status of the profession were represented.

KEY RESULTS: For the 27 submitted procedures, the mean score $( \pm \mathrm{SD})$ was $3.25( \pm 0.48)$ for frequency, 3.10 $( \pm 0.43)$ for uselessness, and $2.63( \pm 0.84)$ for risk.

The Top-5 list obtained with the composite score was as follows:

1. Do not prescribe long-term treatment with proton pump inhibitors without regular reevaluation of the indication

2. Do not administer preventive treatments (e.g., for dyslipidemia, hypertension...) in elderly people with dementia when potential risks outweigh the benefits

3. Do not administer hypnotic medications as first-line treatment for insomnia

4. Do not treat with an anticoagulant for more than 3 months a patient with a first venous thromboembolism occurring in the setting of a major transient risk factor

5. Do not screen for Lyme disease without an exposure history or related clinical examination findings

We found that the composite score was strongly correlated to the risk score $\left(r_{\mathrm{s}}=0.88, p<10^{-5}\right)$ and not to the frequency $\left(r_{\mathrm{s}}=0.06, p=0.75\right)$ or uselessness score $\left(r_{\mathrm{s}}=0.17, p=0.38\right)$. CONCLUSIONS: This Top- 5 list provides an opportunity to discuss appropriate use of health care practices in internal medicine.

Received June 7, 2018

Revised December 17, 2018

Accepted March 27, 2019

Published online June 12, 2019
KEY WORDS: Choosing Wisely; overmedicalization; internal medicine; inappropriate prescribing.

J Gen Intern Med 34(8):1475-85

DOI: $10.1007 / \mathrm{s} 11606-019-05050-2$

(C) Society of General Internal Medicine 2019

\section{INTRODUCTION}

Scientific and technological advances in the medical field have led to the development of new diagnostic procedures and new therapeutic options. Although this process is generally beneficial and desirable, it has also led to the emergence of medical situations of overdiagnosis or overtreatment. These situations can lead to adverse effects for patients and significant additional costs in healthcare and there is now a need of "deimplement" or phase out interventions that are not supported by evidence. ${ }^{1}$ Overmedicalization has been gaining international momentum, as shown in the "Less is more" columns of the JAMA Internal Medicine. ${ }^{2}$ or "Too much medicine" of the British Medical Journal. ${ }^{3}$ The American Board of Internal Medicine launched in 2012 a national project named "Choosing Wisely" which aims to encourage health professionals and patients to engage in dialogue about unnecessary and potentially harmful diagnosis procedures and treatments. ${ }^{4}$, ${ }^{5}$ It was proposed to every American scientific society to create a list called "Five things that doctors and patients should question" sometimes referred to as Top-5 list. This initiative spread rapidly in Canada, Australia, the UK, and Japan. ${ }^{6-8}$

In 2016, the EFIM (European Federation of Internal Medicine), which brings together the national societies of internal medicine and represents over 40,000 internists in Europe, decided to encourage European internal medicine societies to participate in "Choosing Wisely." This call has been relayed by the French Hospital Federation (FHF), a public organization which promotes, informs, and represents public hospitals and medico-social institutions in France. The FHF asked in 2016 each French scientific society to define a Top-5 list. Subsequently, the French National Society of Internal Medicine (SNFMI) created a working group dedicated to this task. The SNFMI is the French leading and only national society in Internal Medicine. It represents internists whatever their 
professional status, working place, practice, or region in every political and public health instance. French Medical Board 2016 data shows that 2219 internists are registered in France and the SNFMI counts 1491 members; thus, we can consider that around $67 \%$ of the total French internists are registered with the SNFMI. ${ }^{9}$ It includes the Junior Internist Association (AJI), which is the only national group of internal medicine residents. It is important to note that French internal medicine residency is a separate specialty that encompasses clinical immunology and general internal medicine. The 5-year residency needed for this specialty is not the core curriculum for other specializations. Another characteristic of internal medicine in France is that more than $90 \%$ of French internists practice in the public system as reported by the French Medical Board. ${ }^{9}$

In this article, we present the result of the SNFMI national survey to define the Top-5 list in internal medicine.

\section{MATERIAL AND METHODS}

\section{Working Group}

A working group (WG) of 15 members ( 7 women and 8 men) was set up in January 2017; it included 9 members of the SNFMI (7 professors or assistant professors and 2 hospital practitioners) and 6 members of the AJI (5 residents and 1 fellow). Three members of the working group worked in a general hospital and the 12 others in academic hospitals.

\section{Phase 1: Selection of Medical Procedures}

In 2017, each member of the WG reviewed the Top-5 lists of Australian, American, English, and Canadian societies of internal medicine, hospital medicine, vascular medicine, rheumatology, infectious diseases, general medicine, geriatrics, and clinical immunology. The members were also encouraged to add procedures from personal experience or other Top-5 lists. Each member selected up to 15 procedures that seemed frequent, unhelpful, potentially risky, and based on no scientific evidence. Then, each procedure was reviewed and discussed by the WG during teleconferences, in order to eliminate duplicate procedures and those that did not reach consensus. For each selected procedure, at least two different members of the WG searched literature for scientific evidence.

\section{Phase 2: National Survey of Internists}

A call for participation was sent by email to all members of the SNFMI and the AJI. Each volunteer had to respond to the email in order to receive a personal link of participation, automatically generated and linked to a unique identifier. The support of the survey was a website that provided access to the questionnaire and the list of the medical procedures selected in phase 1 (each accompanied by at least three and up to ten relevant bibliographic references). The first part of the questionnaire collected demographic information and the second part of the questionnaire allowed for an evaluation of each procedure with a numeric scale using a score between 1 and 5 for its perceived frequency, uselessness, and risk. The order of appearance of medical procedures was random for each participant to avoid bias due to changes in the participant's way of rating medical procedures during the questionnaire (e.g., modification of the concentration level).

\section{Statistical Analysis}

Data were entered into a spreadsheet and imported into $\mathrm{R}$ software (version 3.2.4) for statistical analysis. For each procedure, a composite score was calculated as an unweighted addition of the three scores of frequency, risk, and uselessness. This composite score was used to define the final Top-5 list. Numerical data are presented as absolute numbers, proportion, mean \pm standard deviation (SD), or median \pm interquartile range (IQR). We used Pearson's chi-squared test for categorical variables to compare the demographic characteristics of our sample of participants with the population of the SNFMI and AJI. We calculated correlations between the scores using Spearman rank-order correlation coefficient $\left(r_{\mathrm{s}}\right)$. We used the free R package "FactoMineR" to draw a circle of correlation.

\section{RESULTS}

\section{Phase 1: Selection of Medical Procedures}

A total of 123 medical procedures from 20 Australian, American, British, or Canadian scientific societies were systematically reviewed by each member of the WG. The selection of members of the WG resulted in a list of 49 medical procedures. After subsequent meetings, a list of 27 medical procedures that were agreed upon in the WG was retained (Fig. 1). Four medical procedures came from the personal experience of members of the WG. Table 1 presents these medical procedures and specifies for each item its presence or not in existing Top-5 lists.

\section{Phase 2: National Survey of Internists}

Among the participants 59\% were men $(n=255)$ and the median age was 35 years (IQR, 28-43 years) (Table 2). All French regions, including ultramarine regions, were represented. All the status of the profession participated in the survey with 186 residents (44\%), 74 fellows (17\%), 100 hospital practitioners $(23 \%), 48$ professors or university lecturers $(11 \%)$, and 18 working as independent physicians (4\%). Three hundred fifteen $(77 \%)$ participants worked in university hospitals, $53(13 \%)$ in general public hospitals, $13(3 \%)$ in military hospitals, 20 in private hospitals $(5 \%)$, and 10 in medical offices (2\%).

For the 27 medical procedures, the mean score $( \pm \mathrm{SD})$ was $3.25( \pm 0.48)$ for frequency, $3.10( \pm 0.43)$ for uselessness, and $2.63( \pm 0.84)$ for risk (Fig. 2). Table 3 presents separately the 10 most frequent, the 10 least useful, and the 10 riskiest medical procedures, as reported in the survey. 


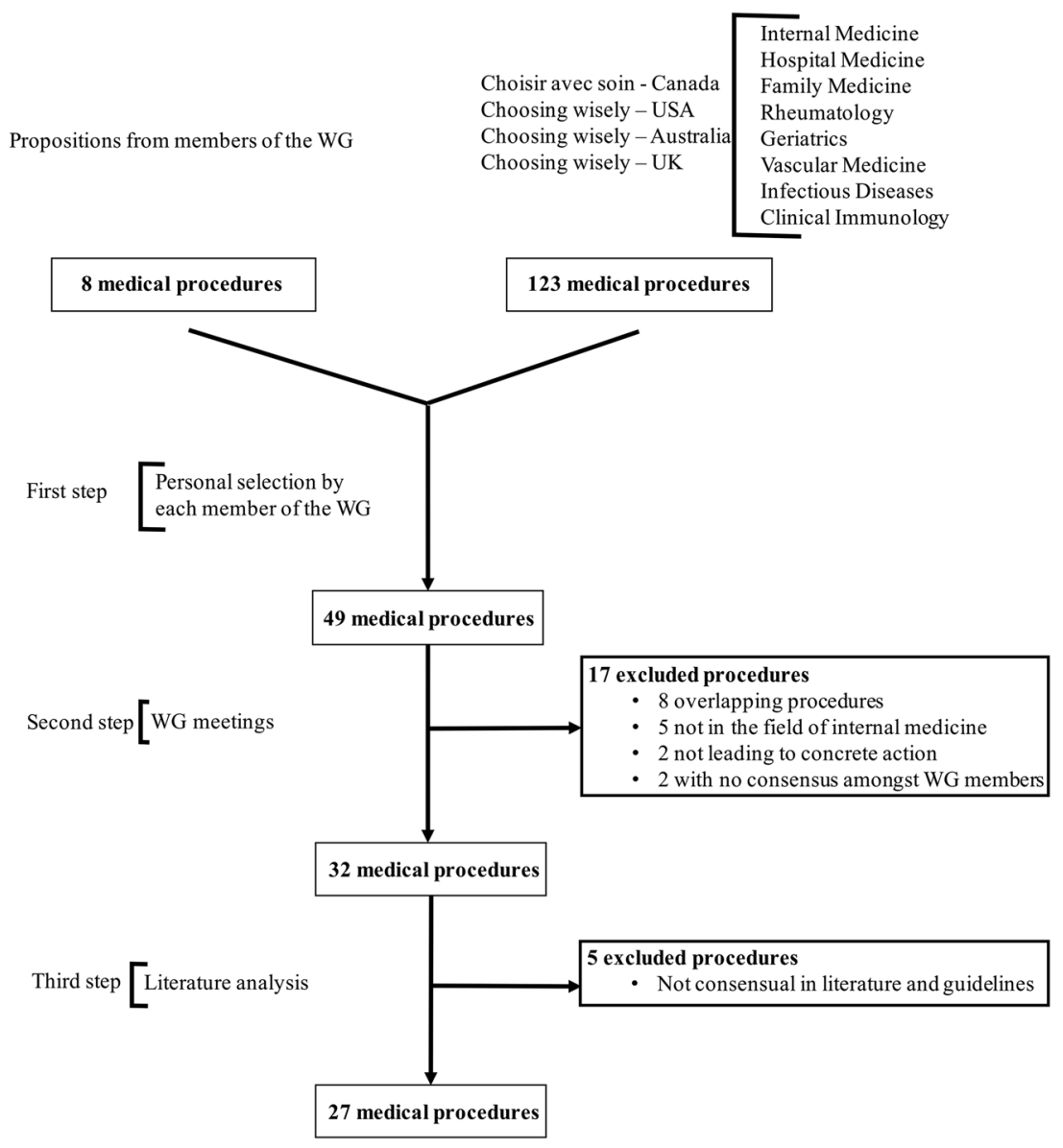

Fig. 1 Steps for the selection of the medical procedures.

The composite score calculated as the unweighted addition of the three scores allowed us to define the French Top-5 list in internal medicine (Table 4):

1. Do not prescribe long-term treatment with proton pump inhibitors without regular reevaluation of the indication

2. Do not administer preventive treatments (e.g., for dyslipidemia, hypertension...) in elderly people with dementia when potential risks outweigh the benefits

3. Do not administer hypnotic medications as first-line treatment for insomnia

4. Do not treat with an anticoagulant for more than 3 months a patient with a first venous thromboembolism (VTE) occurring in the setting of a major transient risk factor

5. Do not screen for Lyme disease without an exposure history or related clinical examination findings

\section{Sample Representativeness}

Table 2 compares the population of the SNFMI including AJI with our sample of participants. There were significant differences between the age breakdown $(p<0.001)$, the professional status $(p=0.001)$, and the working place $(p<0.001)$, reflecting the fact that there was an overrepresentation of young internists, residents, fellows, and physicians working in academic settings.
We repeated our calculations with different groups to determine if these biases could influence the Top-5 list. If we excluded residents $(n=244)$, the five Top- 5 items were exactly the same, the only difference being that the second item ranked third and the third ranked second. If we excluded residents and fellows $(n=170)$, four of the five Top- 5 items were the same, with the replacement of the item on "Lyme test," ranked 5th, by the item "IV > PO," ranked 7th. The 10 items that achieved the highest composite score were exactly the same (but in a slightly different order). If we excluded professors or assistant professors $(n=382)$, four of the five Top-5 items were the same, with the replacement of the fifth item "Lyme test" by the sixth item "Heparin bridging." Finally, if we excluded internists practicing in university hospitals ( $n=115)$, the five Top-5 items were the same but ranked differently: 1. "Hypnotics," 2. "Long-term PPI," 3. "Anticoagulants $>3$ months," 4. "Treatments in dementia," and 5. "Lyme test." The 10 items that achieved the highest composite score were exactly the same.

\section{Relations Between the Scores}

To determine whether the perceived variables (frequency, uselessness, and risk) were independent, we conducted correlation tests between the three scores. There was no correlation between the frequency and the risk score $(r=-0.17, p=0.4)$ nor between the uselessness and the risk score $(r=0.01, p=0.9)$ but there was 
Table 1 List of the 27 Medical Procedures Selected During the First Phase and Evaluated in the National Survey

\begin{tabular}{|c|c|c|}
\hline Medical procedures & Short title & $\begin{array}{l}\text { Presence in Top-5 } \\
\text { lists }\end{array}$ \\
\hline $\begin{array}{l}\text { 1. To test for anti-nuclear } \\
\text { antibody (ANA) without } \\
\text { a clinical or biological } \\
\text { suspicion of systemic lu- } \\
\text { pus erythematosus or } \\
\text { immune-mediated dis- } \\
\text { ease. }\end{array}$ & ANA testing & $\begin{array}{l}\text { - American College } \\
\text { of Rheumatology } \\
\text { - Canadian } \\
\text { Rheumatology } \\
\text { Association }\end{array}$ \\
\hline $\begin{array}{l}\text { 2. To prescribe a strict } \\
\text { salt-free diet, potassium } \\
\text { supplementation, and/or } \\
\text { a proton pump inhibitor } \\
\text { in all patients treated by } \\
\text { long-term steroids. }\end{array}$ & Long-term steroids & $\begin{array}{l}\text { - Added by the } \\
\text { working group }\end{array}$ \\
\hline $\begin{array}{l}\text { 3. To prescribe long-term } \\
\text { treatment with PPI with- } \\
\text { out regular reevaluation } \\
\text { of the indication. }\end{array}$ & Long-term PPI & $\begin{array}{l}\text { - Italian Society of } \\
\text { Internal Medicine } \\
\text { - Royal Australian } \\
\text { College of General } \\
\text { Practitioners }\end{array}$ \\
\hline $\begin{array}{l}\text { 4. To test for } \\
\text { thrombophilia every } \\
\text { patient who develops a }\end{array}$ & $\begin{array}{l}\text { Thrombophilia } \\
\text { testing }\end{array}$ & $\begin{array}{l}\text { - American Society } \\
\text { for Vascular } \\
\text { Medicine }\end{array}$ \\
\hline
\end{tabular}

first episode of deep vein thrombosis (DVT) without clinical or biological arguments for a secondary thrombophilia on initial evaluation.

5. To measure D-dimer

in patients with a strong pretest probability of venous thromboembolism (VTE) or pulmonary embolism.

6. To measure vitamin D without a past history of bone or calcium metabolism disorders.

7. To measure thyroidstimulating hormone (TSH) without a clinical or biological suspicion of thyroid dysfunction. 8 . To screen for a Clostridium difficile infection in the absence of diarrhea.

9. To prescribe a stool test to explore diarrhea without a context of immunosuppression, traveler diarrhea or gravity criteria.

10. To test for Lyme disease without an exposure history or appropriate exam findings.

11. To routinely perform imaging of the carotid arteries or CT of the head for simple syncope without other

neurological symptoms.

12. To prescribe lab tests other than ferritin to explore iron deficiency without a context of inflammatory syndrome. 13. To routinely screen for breast, pulmonary, colorectal, or prostatic

Table 1. (continued)

\begin{tabular}{lll}
\hline \hline Medical procedures & Short title & $\begin{array}{l}\text { Presence in Top-5 } \\
\text { lists }\end{array}$ \\
\hline
\end{tabular}

cancer, without

considering life

expectancy and risks

linked with screening

and potential treatments.

14. To routinely use intravenous perfusion to administer a treatment that could be used by enteral route.

15. To place a urinary catheter for the sole purpose of monitoring urine output.

16. To use heparin bridging therapy during oral anticoagulant interruption for an invasive procedure or surgery without a high thromboembolic risk (such as a mechanical heart valve, an antiphospholipid syndrome, or a recent thromboembolic event). 17. To treat with an anticoagulant for more than 3 months a patient with a first venous thromboembolism (VTE) occurring in the setting of a major transient risk factor.

18. To systematically recommend bed rest following diagnosis of acute deep vein thrombosis (DVT). 19. To screen and/or to treat asymptomatic bacteriuria (with the exception of pregnant

Lyme test patients). - American College
of Rheumatology

CT syncope

Iron deficiency

- Internal Medicine Society of Australia and New Zealand - Canadian Society of Internal Medicine - Canadian Society of Hospital Medicine - Added by the working group

Cancer screening - American Society of General Internal Medicine
20. To transfuse red blood cells into a patient with a hemoglobin superior to $8 \mathrm{~g} / \mathrm{dl}$ (with the exception of acute

- American Geriatrics Society

IV $>$ PO

Urinary catheter

Heparin bridging

Anticoagulant $>$ 3 months

Bed rest

Asymptomatic bacteriuria

\author{
- Italian Society of \\ Internal Medicine \\ - Canadian Geriatrics \\ Society \\ - Canadian \\ Association of \\ Medical \\ Microbiology and \\ Infectious Disease \\ - American Society \\ for Post-Acute and \\ Long-Term Care \\ Medicine \\ - Canadian Society \\ of Internal Medicine \\ - Canadian Society \\ of Hospital Medicine \\ - American Society \\ of Hospital Medicine \\ - Canadian \\ Hematology Society \\ - American Society \\ of Hematology
}

- American Society of Hematology
- Italian Society of Internal Medicine - American Physical Therapy Association

- Australian and New Zealand Society for Geriatric Medicine

- Australasian

Society for Infectious Diseases

- American Geriatrics Society

- Infectious Diseases

Society of America

- Canadian Society

of Hospital Medicine

- Canadian Geriatrics

Society

- American Society

for Post-Acute and

Long-Term Care

Medicine

Transfusion $>8 \mathrm{~g} /$ - American Society

dL of Hospital Medicine

- Canadian Society

of Internal Medicine 
Table 1. (continued)

\begin{tabular}{l}
\hline Medical procedures \\
\hline coronary syndrome or \\
severe thrombopenia).
\end{tabular}

21. To associate proton pump inhibitors (PPI) when beginning NSAID or antiplatelet drug in patients who do not have a high risk of ulcer disease.

22. To administer hypnotic medications as first-line treatment for insomnia.

23. To repeat blood tests in the case of stable or favorable clinical evolution.

24. To ask for routine multiple daily selfmonitoring of glucose in adult patients with stable type 2 diabetes on agents that do not cause hypoglycemia.

\section{To administer} preventive treatments (e.g., for dyslipidemia hypertension...) in risks outweigh the benefits $\dagger$

26. To administer dopamin antagonist antiemetic drugs (e.g., metoclopramide) in nausea accompanying acute diseases.

27. To use

fluoroquinolones while

there are other alternative antibiotics in a patient with a long-term steroids treatment.

Hypnotics

Repeat blood tests

Glucose selfmonitoring

Treatments in dementia

Antiemetic drugs elderly people with dementia when potential

$\begin{array}{ll}\text { PPI NSAID } & \text { of Anesthesiologists } \\ & \text { - American Society } \\ & \text { of Hospital } \\ & \text { Medicine* }\end{array}$

- Australian New Zealand Society for Geriatric Medicine

- American Geriatrics

Society

- Canadian Society of Hospital Medicine - Canadian Geriatrics Society

- American Academy of Sleep Medicine

- American Society of Hospital Medicine - Canadian Society of Internal Medicine - Critical Care Societies

Collaborative

- American

Association of Blood Banks

- Royal Australian College of General

Practitioners

- American Society of General Internal Medicine

- College of Family Physicians of Canada - Royal College of General Practitioners (UK)*

- American Society for Post-Acute and Long-Term Care Medicine*

- Added by the working group

$\begin{array}{ll}\text { Fluoroquinolones } & \text { - American } \\ \text { use } & \text { Urogynecologic } \\ & \text { Society } \\ & \text { - American } \\ & \text { Urological } \\ & \text { Association* }\end{array}$

*These procedures are close to the ones that are selected in the study but are not similar (e.g., "To administer preventive treatments (e.g., for dyslipidemia, hypertension...) in elderly people with dementia." vs "Do not routinely prescribe lipid-lowering medications in individuals with a limited life expectancy." (American Society for Post-Acute and LongTerm Care Medicine))

\%"When potential risks outweigh the benefits" was added after review and discussion between the members of the working group

a significant inverse correlation between the frequency and the uselessness score $(r=-0.5, p=0.008)$.

To determine which score(s) weighted most in the final ranking of items, we conducted a correlation test between the composite score (used for the Top-5 list) and each of the three scores. There was no correlation between the final score and the frequency score $(r=0.06, p=0.75)$ nor between the final score and the uselessness score $(r=0.17, p=0.38)$ but

Table 2 Demographical Characteristics of Participants in the National Survey

\begin{tabular}{|c|c|c|c|}
\hline & $\begin{array}{l}\text { Participants } \\
\text { Number }(\%) \\
(n=430)\end{array}$ & $\begin{array}{l}\text { SNFMI and } \\
\text { AJI members } \\
\text { Number }(\%) \\
(n=1850) *\end{array}$ & $\begin{array}{l}\text { Chi- } \\
\text { square } \\
\text { test } \\
p \text { value }\end{array}$ \\
\hline \multicolumn{4}{|l|}{ Age (years) } \\
\hline $20-30$ & $187(43)$ & $360(26)$ & $<0.001$ \\
\hline $31-40$ & $125(29)$ & $384(28)$ & \\
\hline $41-50$ & $52(12)$ & $207(15)$ & \\
\hline $51-60$ & 49 (11) & $232(17)$ & \\
\hline$>60$ & $17(4)$ & 195 (14) & \\
\hline Male sex & $255(59)$ & $877(59)$ & 0.90 \\
\hline \multicolumn{4}{|l|}{ Professional status } \\
\hline Resident & $186(44)$ & $596(40)$ & 0.001 \\
\hline Fellow & $74(17)$ & $177(12)$ & \\
\hline Professor/ & $48(11)$ & $114(8)$ & \\
\hline \multicolumn{4}{|l|}{ professor } \\
\hline Private doctor & $18(4)$ & $67(5)$ & \\
\hline Retired & $4(1)$ & $14(1)$ & \\
\hline \multicolumn{4}{|l|}{ Working place } \\
\hline University & $315(77)$ & $366(40)$ & $<0.001$ \\
\hline hospital & & & \\
\hline General public & $53(13)$ & $366(40)$ & \\
\hline \multicolumn{4}{|l|}{ hospital } \\
\hline Military hospital & $13(3)$ & $19(2)$ & \\
\hline Private hospital & $20(5)$ & $101(11)$ & \\
\hline Private office & $10(2)$ & $44(5)$ & \\
\hline \multicolumn{4}{|c|}{ Region of practice } \\
\hline Auvergne- & $53(13)$ & $75(9)$ & 0.26 \\
\hline \multicolumn{4}{|l|}{ Rhône-Alpes } \\
\hline Bourgogne- & $18(4)$ & $31(4)$ & \\
\hline \multicolumn{4}{|l|}{ Franche-Comté } \\
\hline Bretagne & $13(3)$ & $37(4)$ & \\
\hline Centre-Val de & 17 (4) & $22(3)$ & \\
\hline \multicolumn{4}{|l|}{ Loire } \\
\hline Corse & $1(0.2)$ & $2(0.2)$ & \\
\hline Grand Est & $43(10)$ & $89(10)$ & \\
\hline Hauts-de-France & $20(5)$ & $52(6)$ & \\
\hline Île-de-France & $127(30)$ & $243(29)$ & \\
\hline Normandie & $16(4)$ & $42(5)$ & \\
\hline Nouvelle- & $29(7)$ & $59(7)$ & \\
\hline \multicolumn{4}{|l|}{ Aquitaine } \\
\hline Occitanie & $33(8)$ & $75(9)$ & \\
\hline Pays de la Loire & $18(4)$ & $42(5)$ & \\
\hline Provence-Alpes- & $31(7)$ & $65(8)$ & \\
\hline \multicolumn{4}{|l|}{ Côte d'Azur } \\
\hline Overseas France & $5(1)$ & $17(2)$ & \\
\hline
\end{tabular}

*Data are missing for some participants. Proportions are calculated among available data 


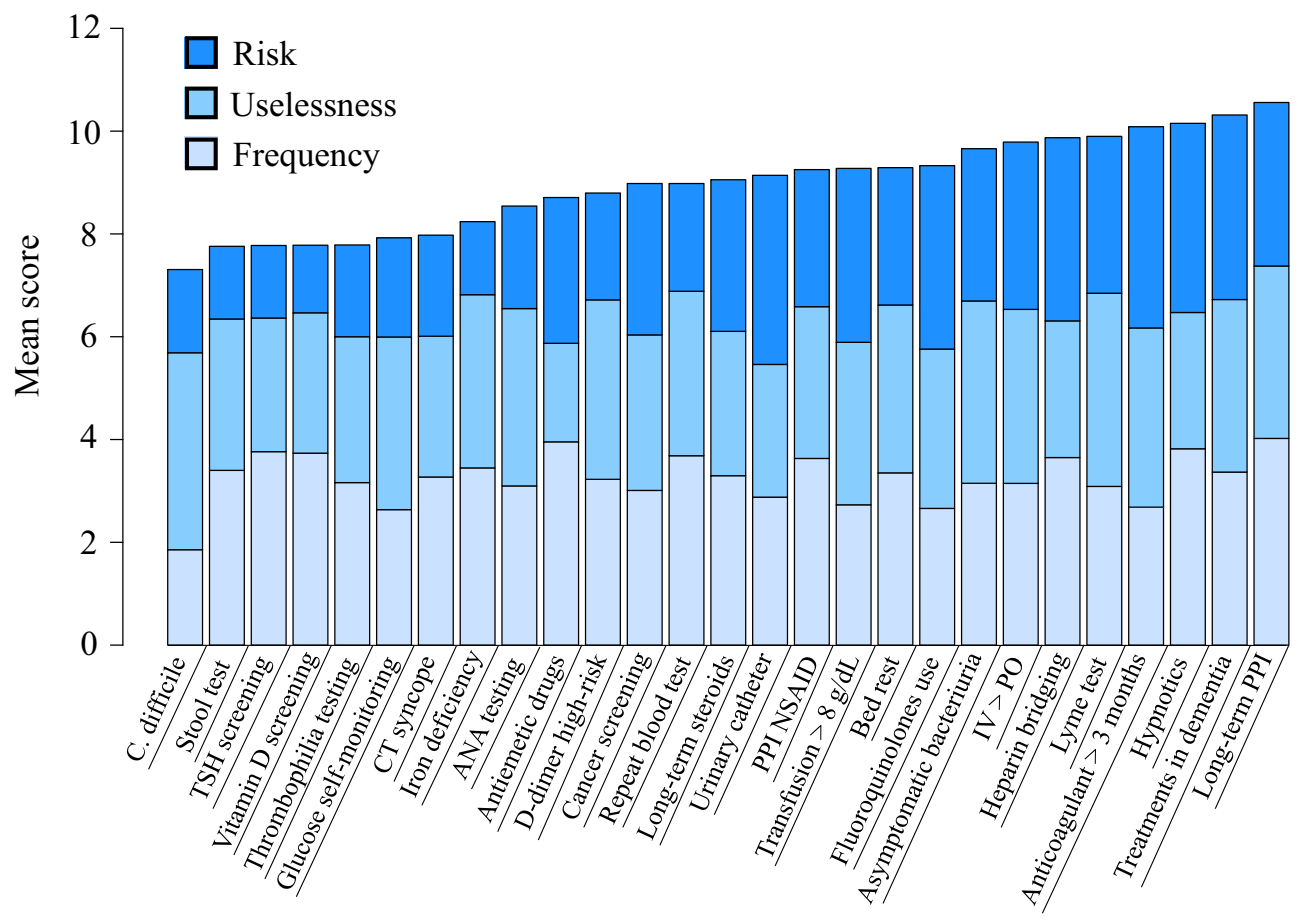

Fig. 2 Score of frequency, uselessness, and risk of the 27 medical procedures.

there was a strong and significant correlation between the final score and the risk score $\left(r=0.89, p<10^{-5}\right)$. A circle of correlation summarizing these results is presented in Fig. 3.

\section{DISCUSSION}

The French National Society of Internal Medicine and the Junior Internist Association participated in a national webbased survey to determine a Top-5 list in internal medicine. The five following procedures were selected:

1. Do not prescribe long-term treatment with proton pump inhibitors without regular reevaluation of the indication Proton-pump inhibitors (PPIs) are one of the most prescribed treatments in France and represent a major cost for national health insurance, estimated at one billion per year by French social welfare. ${ }^{10}$ The main indications for longterm use are recurrent gastroesophageal reflux disease, Barrett's esophagus, and prevention of gastroduodenal lesions in patients at risk treated with NSAIDs. ${ }^{11}$ However, it is estimated that a large number of prescriptions (between 25 and $70 \%$ ) are made in out-of-label clinical situations. ${ }^{12}$ Moreover, chronic intake of PPIs is associated with an increased risk of malabsorption (vitamin B12, magnesium, calcium, iron), osteoporotic fractures, infections (including Clostridium difficile pseudomembranous colitis), digestive neoplasia, drug interactions, dementia, and renal failure. ${ }^{13}$ Therefore, regular reassessment of the indication and dosage of long-term PPIs is essential. PPIs are already mentioned in many Top-5 lists (e.g., Italian society of Internal Medicine, Royal Australian College of
General Practitioners) and many tools already exist to help physicians deprescribe PPIs. ${ }^{14,} 15$

2. Do not administer preventive treatments (e.g., for dyslipidemia, hypertension...) in elderly people with dementia when potential risks outweigh the benefits

The data supporting the use of preventive treatments in older people is scarce especially in patients suffering from dementia. $^{16}$ The US Preventive Services Task Force concluded in 2016 that the current evidence is insufficient to assess the balance of benefits and harms of the use of statins in elderly patients. ${ }^{17}$ Antihypertensive medications have been found to increase the risk of serious fall injuries among communityliving adults older than 70 years and the risk even increased among the frailest patients. ${ }^{18}$ In a recent study assessing more than 500,000 patients' files, an increase in the number of drugs administered to patients during their last year of life was observed, including drugs for the long-term prevention of chronic diseases. ${ }^{19}$ Thus, physicians should always take into account the degree of dementia and wonder whether a patient life expectancy is longer than the time needed for the medication to achieve its benefit. ${ }^{20}$ This proposition does not mean that all preventive treatments should be stopped in older people with dementia but that the potential harms versus benefits of each drug prescribed in this population should be carefully weighed and discussed with the patient and his family.

3. Do not administer hypnotic medications as first-line treatment for insomnia

Insomnia is a common pathology which can be exacerbated during hospitalization. ${ }^{21,} 22$ Many practitioners use benzodiazepines and other hypnotics as first-line 
Table 3 The 10 Most Frequent, Riskiest, and Least Useful Medical Procedures According to the National Survey of French Internists

\begin{tabular}{|c|c|c|c|c|c|}
\hline $\begin{array}{l}\text { The } 10 \text { most frequent } \\
\text { procedures }\end{array}$ & $\begin{array}{l}\text { Mean } \\
\text { frequency } \\
\text { score }(/ 5)\end{array}$ & The 10 riskiest procedures & $\begin{array}{l}\text { Mean } \\
\text { risk } \\
\text { score }\end{array}$ & The 10 least useful procedures & $\begin{array}{l}\text { Mean } \\
\text { uselessness } \\
\text { score }(/ 5)\end{array}$ \\
\hline
\end{tabular}

To prescribe long-term treatment with PPI without regular reevaluation of the indication.

To administer dopamin antagonist

3.95

antiemetic drugs (e.g.

metoclopramide) in nausea

accompanying acute diseases.

To administer hypnotic

medications as first-line treatment

for insomnia.

To measure thyroid-stimulating hormone (TSH) without a clinical or biological suspicion of thyroid dysfunction.

To measure vitamin $\mathrm{D}$ without a past history of bone or calcium metabolism disorders.

To repeat blood tests in the case of stable or favorable clinical evolution.
4.02 To use fluoroquinolones whi
there are other alternative
antibiotics in a patient with long-term steroids treatment.

To use heparin bridging therapy during oral anticoagulant interruption for an invasive procedure or surgery without a high thromboembolic risk (such as a mechanical heart valve, an antiphospholipid syndrome, or a recent thromboembolic

event).

To use heparin bridging therapy

during oral anticoagulant

interruption for an invasive procedure or surgery without a high thromboembolic risk (such as a mechanical heart valve, an antiphospholipid syndrome, or a recent thromboembolic event).

To associate proton pump inhibitors (PPI) when beginning NSAID or antiplatelet drug in patients who do not have a high risk of ulcer disease.

To prescribe lab tests other than ferritin to explore iron deficiency without a context of inflammatory syndrome.

To prescribe a stool test to explore diarrhea without a context of immunosuppression, traveler diarrhea or gravity criteria.

for more than 3 months a thromboembolism (VTE) occurring in the setting of a major transient risk factor. medications as first-line treatment for insomnia.

To place a urinary catheter for

To administer preventive treatments (e.g., for dyslipidemia, hypertension...) in elderly people with dementia.

To transfuse red blood cells into a patient with an hemoglobin superior to $8 \mathrm{~g} / \mathrm{dl}$ (with the exception of acute coronary syndrome or severe thrombopenia).

To routinely use intravenous perfusion to administer a treatment that could be used by enteral route.

To prescribe long-term treatment with PPI without regular reevaluation of the indication.

To test for Lyme disease without an exposure history or appropriate exam findings.

$(/ 5)$ To screen for a Clostridium

3.91 of diarrhea.

To test for Lyme disease without an exposure history or appropriate exam findings.
3.68 To screen and/or to treat asymptomatic bacteriuria (with the exception of pregnant patients).

3.59 To measure D-dimer in patients with a strong pretest probability of venous thromboembolism (VTE) or pulmonary embolism. To treat with an anticoagulant for more than 3 months a patient with a first venous thromboembolism (VTE) occurring in the setting of a major transient risk factor.

To test for anti-nuclear antibody (ANA) without a clinical or biological suspicion of systemic lupus erythematosus or immune-mediated disease.

3.56

To routinely use intravenous perfusion to administer a treatment that could be used by enteral route.

To prescribe lab tests other than ferritin to explore iron deficiency without a context of inflammatory syndrome.

To ask for routine multiple daily self-glucose monitoring in adult patients with stable type 2 diabetes on agents that do not cause hypoglycemia.

To administer preventive treatments (e.g., for dyslipidemia, hypertension...) in elderly people with dementia. treatment for insomnia. However, despite the efficacy of hypnotics in insomnia, many studies have shown deleterious effects associated to their use, as an increase in the risk of falls, road accidents, cognitive disorders, and delirium, particularly in the elderly. ${ }^{23-25}$ The therapeutic approach proposed to the patient suffering from insomnia must be multiple, and drugs, toxic, or other risk factors for insomnia should be systematically investigated. Nonpharmacological treatment, such as cognitive-behavioral therapy, should be offered as first-line treatment, as recommended in the latest European and American guidelines. 21,26

4. Do not treat with an anticoagulant for more than 3 months a patient with a first venous thromboembolism (VTE) occurring in the setting of a major transient risk factor Anticoagulant treatments have been shown to be effective to prevent the risk of thromboembolic recurrence after a proximal deep venous thrombosis (DVT). The optimal 
Table 4 The French Top-5 list in Internal Medicine

\begin{tabular}{|c|c|c|c|c|}
\hline & $\begin{array}{l}\text { Mean Frequency } \\
\text { score }(/ 5)\end{array}$ & $\begin{array}{l}\text { Mean Risk } \\
\text { score }(/ 5)\end{array}$ & $\begin{array}{l}\text { Mean Uselessness } \\
\text { score }(/ 5)\end{array}$ & $\begin{array}{l}\text { Mean total } \\
\text { score }(/ 15)\end{array}$ \\
\hline $\begin{array}{l}\text { To prescribe long-term treatment with PPI without regular reevaluation of } \\
\text { the indication. }\end{array}$ & 4.02 & 3.18 & 3.36 & 10.56 \\
\hline $\begin{array}{l}\text { To administer preventive treatments (e.g. for dyslipidemia, } \\
\text { hypertension...) in elderly people with dementia. }\end{array}$ & 3.37 & 3.59 & 3.36 & 10.32 \\
\hline To administer hypnotic medications as first-line treatment for insomnia. & 3.82 & 3.68 & 2.65 & 10.15 \\
\hline $\begin{array}{l}\text { To treat with an anticoagulant for more than three months a patient with a } \\
\text { first venous thromboembolism (VTE) occurring in the setting of a major } \\
\text { transient risk factor. }\end{array}$ & 2.68 & 3.91 & 3.49 & 10.08 \\
\hline $\begin{array}{l}\text { To test for Lyme disease without an exposure history or appropriate } \\
\text { exam findings. }\end{array}$ & 3.09 & 3.05 & 3.76 & 9.90 \\
\hline
\end{tabular}

duration of anticoagulation rests on the balance between the hemorrhagic risk and the reduction of thromboembolic recurrences. When factors favoring DVT are identified, the risk of recurrence after DVT is almost half as high as when they are absent and the prolongation of anticoagulant treatment is associated with an increase in the number of major bleeding complications. ${ }^{27,}{ }^{28}$ These elements support a short duration of treatment for DVT following a major transient risk factor. Treatment of 6 months compared to 3 months in case of provoked DVT does not bring benefits in terms of reduction of recurrence, but increases the hemorrhagic risk by approximately 2.5 times. ${ }^{29}$ These recommendations do not apply in the case of non-controlled risk factors (including progressive cancers), or in cases of recurrent DVT. ${ }^{29,30}$

5. Do not screen for Lyme disease without an exposure history or related clinical examination findings

The inappropriate use of testing for Lyme disease is frequent and can lead to wasteful health care spending and significant patient harm. Lyme testing has been consistently found to be ordered inappropriately in more than $50 \%$ of cases in endemic areas and even more in nonendemic areas. ${ }^{31,} 32$ In a recent study in the Netherlands, only $9 \%$ of the serological testing for Lyme were supported by guidelines. ${ }^{33}$ Unfortunately, many patients who are
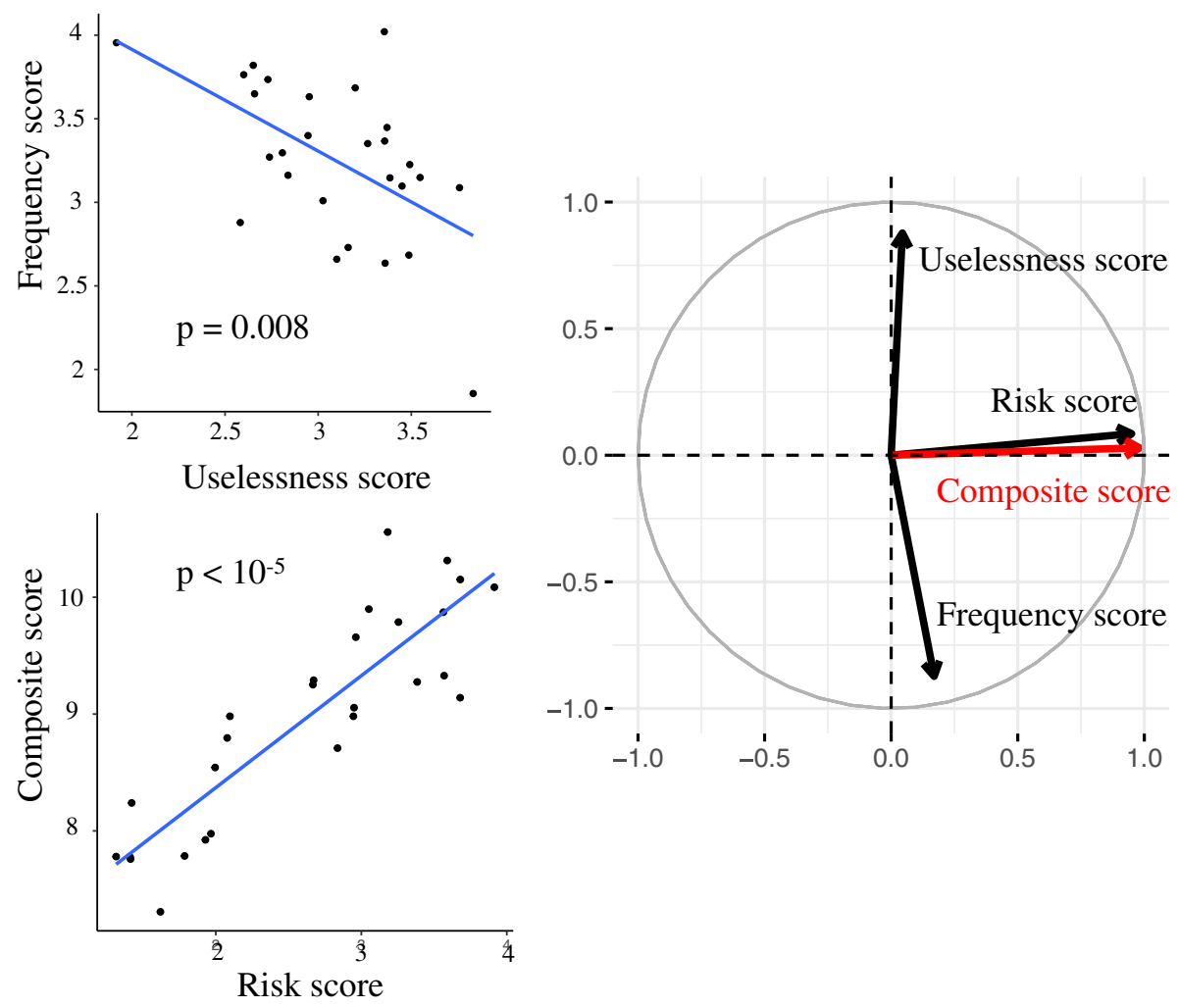

Fig. 3 Correlation between the scores and circle of correlation. Legend: left panel: graphical representation of the Spearman's correlation between the frequency and the uselessness score (top) and between the risk score and the composite score (bottom). Each point represents one of the 27 medical procedures. Right panel: circle of correlation with the scores represented by their correlations. The composite score, which is an unweighted addition of the frequency, risk, and uselessness scores (black arrows), is represented by a red arrow. 
inappropriately tested receive antibiotics irrespective of serologic results, resulting in the inappropriate use of antibiotics that may cause severe adverse events in patients. $^{32,34,35}$ Testing for Lyme should only be considered in patients with an appropriate exposure history and objective findings on clinical examination. ${ }^{36}$ Clinical situations associated with inappropriate use of testing include patients reporting asymptomatic tick bites or patients mentioning nonspecific symptoms such as chronic fatigue or chronic diffuse arthralgias and myalgias, even in endemic areas. ${ }^{32,}{ }^{37}$ As it is the case in the USA, Lyme disease has recently become one of the most widely debated medical subjects in France.

This Top-5 list has been endorsed by the SNFMI, the only internal medicine society in France. We relied both on previously published lists but also on the personal experience of each member to propose new medical behaviors. This allowed to consider seven original procedures and evaluate four in the national study. As it has been shown that many Choosing Wisely recommendations are based on expert consensus or disease-oriented evidence, ${ }^{38,39}$ we carried out a national webbased survey to reflect the opinion of the French internists. We estimate that with 430 responses, approximately $14 \%$ of the total number of internists at work or undergoing training in France responded to this survey. To our knowledge, this Top-5 list in internal medicine has been compiled with one of the highest numbers of participating physicians. ${ }^{40-45}$ Moreover, the fact that $44 \%$ of participants were residents is original and encouraging. Given that today's residents will be the prescribers of tomorrow, it seems important to raise early awareness of the problem of overmedicalization.

The use of a composite score is original and, to our knowledge, has not been used in previous Top- 5 lists. This allowed us to study the relationship between the perceived frequency, uselessness, and risk score for each time. We found a significant inverse correlation between frequency and uselessness scores in this study. This could be interpreted as the fact that the more a practice was perceived as useless the less it was perceived as frequent. On the contrary, the risk score in our study was not correlated to the uselessness and frequency scores. Using correlation tests, we found that the composite score, which is a simple addition of the frequency, risk, and uselessness score, was strongly correlated only to the risk score. Thus, the evaluation of the perceived risk was the most relevant in our study and could suggest that the risk score is the most important when elaborating a Top-5 list.

This study has several limitations. First of all, we did not involve the patients' point of view during this survey. Yet, choosing wisely aims to select practices that should lead to a discussion between physicians and patients. ${ }^{46}$ Involving patients could help raise awareness of the issues and risks of overmedicalization. ${ }^{38,47}$ Further work will need to consider codesign Top-5 lists with patients. ${ }^{48}$ Another limitation is the high attrition rate despite our work to engage French internists in the survey. This is a common caveat of web-based surveys, especially when addressing a large population, and should be considered when planning Top-5 lists based on an internet questionnaire. ${ }^{49}$, ${ }^{50}$ Another concern was the risk of bias due to the high proportion of residents and the high proportion of physicians working in university hospitals and academic physicians among the participants. However, subsequent statistical analyses showed that the final Top-5 list would have been the same or shared 4 items out of 5 when varying the population. Finally, it should be noted that Top-5 lists are not intended to eliminate the use of the selected procedures. They only encourage physicians and patients to discuss their use and this may be particularly relevant for the second procedure of this Top-5 lists addressing the prescription in older people with dementia.

This list was produced as part of an EFIM initiative and joins other European lists published in internal medicine in Italy, Switzerland, and Germany. ${ }^{41,51,52}$ Next steps will have to focus on the ways to implement this Top-5 list and to evaluate its impact, including potentially negative consequences. Physicians need to be challenged to question their practices and the results of our study could be the starting point of French national communication campaigns.

Acknowledgments: We thank the SNFMI (French National Society of Internal Medicine) and the Junior Internist Association (AJI) for their support for this work.

We thank the FHF (Féderation Hospitalière de France) and the EFIM (European Federation of Internal Medicine) which were at the origin of this work.

We thank Thibaud Pitel and the Sentinelles network for their assistance in carrying out the web-based survey.

We thank the volunteers who tested the website and all the participants in the survey.

We are grateful to three anonymous reviewers whose insight improved this article.

Corresponding Author: Nathan Peiffer-Smadja, MD, MS; Assistance Publique - Hôpitaux de ParisHôpital Bichat-Claude Bernard, Paris, France (e-mail: nathan.psmadja@gmail.com).

\section{Compliance with Ethical Standards:}

Conflict of Interest: The authors declare that they do not have a conflict of interest.

\section{REFERENCES}

1. Prasad V, Ioannidis JP. Evidence-based de-implementation for contradicted, unproven, and aspiring healthcare practices. Implement Sci 2014;9:1. https://doi.org/10.1186/1748-5908-9-1.

2. Grady D, Redberg RF. Less is more: how less health care can result in better health. Arch Intern Med 2010;170(9):749-750. https://doi.org/10. 1001 /archinternmed.2010.90

3. Too much medicine. Br Med J. http://www.bmj.com/too-much-medicine. Accessed 25 Oct 2017.

4. Sox H, Blank L, Cohen J, ABIM Foundation. American Board of Internal Medicine, Foundation A-A, Medicine AC of P-AS of IMEF of I. Medical professionalism in the new millennium: a physician charter. Ann Intern Med 2002; 136(3):243-246.

5. Volpp KG, Loewenstein G, Asch DA. Choosing wisely: low-value services, utilization, and patient cost sharing. JAMA. 2012;308(16):1635-1636. https://doi.org/10.1001/jama.2012.13616.

6. Chow SL, Carter Thorne J, Bell MJ, et al. Choosing wisely: the Canadian Rheumatology Association's list of 5 items physicians and patients should question. J Rheumatol 2015;42(4):682-689. https://doi. org/10.3899/jrheum.141140. 
7. Malhotra A, Maughan D, Ansell J, et al. Choosing Wisely in the UK: the Academy of Medical Royal Colleges' initiative to reduce the harms of too much medicine. BMJ. 2015;350:h2308.

8. Vogel L. Choosing Wisely around the world. CMAJ. 2015;187(11):E3412. https://doi.org/10.1503/cmaj.109-5111.

9. Conseil National de l'Ordre des Médecins. Atlas de La Démographie Médicale En France.; 2016.

10. Rapports à la Comission des comptes de la sécurité sociale. Les Prescriptions d'IPP.; 2009. http://www.securite-sociale.fr/IMG/pdf/ ccss200910_fic-10-3.pdf.

11. Freedberg DE, Kim LS, Yang Y-X. The Risks and Benefits of Long-term Use of Proton Pump Inhibitors: Expert Review and Best Practice Advice From the American Gastroenterological Association. Gastroenterology. 2017;152(4):706-715. https://doi.org/10.1053/j.gastro.2017.01.031.

12. Boghossian TA, Rashid FJ, Thompson W, et al. Deprescribing versus continuation of chronic proton pump inhibitor use in adults. Cochrane Database Syst Rev 2017;3:CD011969. https://doi.org/10.1002/ 14651858.CD011969.pub2.

13. Sheen E, Triadafilopoulos G. Adverse effects of long-term proton pump inhibitor therapy. Dig Dis Sci 2011;56(4):931-950. https://doi.org/10. 1007/s10620-010-1560-3.

14. Farrell B, Pottie K, Thompson W, et al. Deprescribing proton pump inhibitors: Evidence-based clinical practice guideline. Can Fam Physician 2017:63(5):354-364

15. Deprescribing.org. Evidence-based deprescribing algorithm for proton pump inhibitors. http://www.open-pharmacy-research.ca/wordpress/ wp-content/uploads/ppi-deprescribing-algorithm-cc.pdf. Published 2016. Accessed 28 Nov 2017.

16. Narayan SW, Nishtala PS. Discontinuation of Preventive Medicines in Older People with Limited Life Expectancy: A Systematic Review. Drugs Aging 2017;34(10):767-776. https://doi.org/10.1007/s40266-0170487-1.

17. US Preventive Services Task Force, Bibbins-Domingo K, Grossman DC et al. Statin Use for the Primary Prevention of Cardiovascular Disease in Adults. JAMA. 2016;316(19):1997. https://doi.org/10.1001/jama.2016. 15450.

18. Tinetti ME, Han L, Lee DSH, et al. Antihypertensive medications and serious fall injuries in a nationally representative sample of older adults. JAMA Intern Med 2014;174(4):588-595. https://doi.org/10.1001/ jamainternmed.2013.14764.

19. Morin L, Vetrano DL, Rizzuto D, Calderon-Larranaga A, Fastbom J, Johnell K. Choosing Wisely? Measuring the Burden of Medications in Older Adults near the End of Life: Nationwide, Longitudinal Cohort Study. Am J Med 2017;130(8):927-936.e9. https://doi.org/10.1016/j.amjmed. 2017.02.028.

20. Holmes HM, Hayley DC, Alexander GC, Sachs GA. Reconsidering medication appropriateness for patients late in life. Arch Intern Med 2006;166(6):605-609. https://doi.org/10.1001/archinte.166.6.605.

21. Riemann D, Baglioni C, Bassetti C, et al. European guideline for the diagnosis and treatment of insomnia. J Sleep Res 2017. https://doi.org/ $10.1111 /$ jsr. 12594

22. Young JS, Bourgeois JA, Hilty DM, Hardin KA. Sleep in hospitalized medical patients, part 1: factors affecting sleep. J Hosp Med 2008;3(6):473-482. https://doi.org/10.1002/jhm.372.

23. Finkle WD, Der JS, Greenland S, et al. Risk of fractures requiring hospitalization after an initial prescription for zolpidem, alprazolam, lorazepam, or diazepam in older adults. J Am Geriatr Soc 2011;59(10):1883-1890. https://doi.org/10.1111/j.1532-5415.2011. 03591.x.

24. Glass J. Sedative hypnotics in older people with insomnia: meta-analysis of risks and benefits. BMJ. 2005;331(7526):1169-0. https://doi.org/10. 1136/bmj.38623.768588.47.

25. Airagnes G, Pelissolo A, Lavallée M, Flament M, Limosin F. Benzodiazepine Misuse in the Elderly: Risk Factors, Consequences, and Management. Curr Psychiatry Rep 2016;18(10). https://doi.org/10.1007/ s11920-016-0727-9.

26. Gaseem A, Kansagara D, Forciea MA, Cooke M, Denberg TD Management of Chronic Insomnia Disorder in Adults: A Clinical Practice Guideline From the American College of Physicians. Ann Intern Med 2016;165(2):125-133. https://doi.org/10.7326/M15-2175.

27. Boutitie F, Pinede $\mathbf{L}$, Schulman S, et al. Influence of preceding length of anticoagulant treatment and initial presentation of venous thromboembolism on risk of recurrence after stopping treatment: analysis of individual participants' data from seven trials. BMJ. 2011;342:d3036.

28. Middeldorp S, Prins MH, Hutten BA. Duration of treatment with vitamin $\mathrm{K}$ antagonists in symptomatic venous thromboembolism. Cochrane Database Syst Rev 2014;(8):CD001367. https://doi.org/10. 1002/14651858.CD001367.pub3.

29. Kearon C, Akl EA, Comerota AJ, et al. Antithrombotic therapy for VTE disease: Antithrombotic Therapy and Prevention of Thrombosis, 9th ed: American College of Chest Physicians Evidence-Based Clinical Practice Guidelines. Chest. 2012;141(2 Suppl):e419S-e496S. https://doi.org/10. 1378/chest.11-2301.

30. Heit JA. Predicting the risk of venous thromboembolism recurrence. Am J Hematol 2012;87 Suppl 1:S63-7. https://doi.org/10.1002/ajh.23128.

31. Ley C, Le C, Olshen EM, Reingold AL. The use of serologic tests for Lyme disease in a prepaid health plan in California. JAMA. 1994;271(6):460463.

32. Dessau RB, van Dam AP, Fingerle V, et al. To test or not to test? Laboratory support for the diagnosis of Lyme borreliosis: a position paper of ESGBOR, the ESCMID study group for Lyme borreliosis. Clin Microbiol Infect 2017. https://doi.org/10.1016/j.cmi.2017.08.025.

33. Coumou J, Hovius JWR, van Dam AP. Borrelia burgdorferi sensu lato serology in the Netherlands: guidelines versus daily practice. Eur J Clin Microbiol Infect Dis 2014;33(10):1803-1808. https://doi.org/10.1007/ s10096-014-2129-4

34. Lantos PM, Branda JA, Boggan JC, et al. Poor Positive Predictive Value of Lyme Disease Serologic Testing in an Area of Low Disease Incidence. Clin Infect Dis 2015;61(9):1374-1380. https://doi.org/10.1093/cid/ civ584

35. Marzec NS, Nelson C, Waldron PR, et al. Serious Bacterial Infections Acquired During Treatment of Patients Given a Diagnosis of Chronic Lyme Disease - United States. MMWR Morb Mortal Wkly Rep 2017;66(23):607-609. https://doi.org/10.15585/mmwr.mm6623a3.

36. Wormser GP, Dattwyler RJ, Shapiro ED, et al. The clinical assessment, treatment, and prevention of lyme disease, human granulocytic anaplasmosis, and babesiosis: clinical practice guidelines by the Infectious Diseases Society of America. Clin Infect Dis 2006;43(9):1089-1134. https://doi.org/10.1086/508667.

37. Markowicz M, Kivaranovic D, Stanek G. Testing patients with nonspecific symptoms for antibodies against Borrelia burgdorferi sensu lato does not provide useful clinical information about their aetiology. Clin Microbiol Infect 2015;21(12):1098-1103. https://doi.org/10.1016/j.cmi. 2015.08.005.

38. Horvath $\mathbf{K}$, Siebenhofer A. The Choosing Wisely Initiative: A critical analysis with a special focus on primary care. Z Evid Fortbild Qual Gesundh Wes 2017. https://doi.org/10.1016/j.zefq.2017.10.015.

39. Lin KW, Yancey JR. Evaluating the Evidence for Choosing Wisely TM in Primary Care Using the Strength of Recommendation Taxonomy (SORT). JABFM. 2016;29(4):512-515. https://doi.org/10.3122/jabfm.2016.04. 160003.

40. Cho HJ, Wray CM, Maione S, et al. Right Care in Hospital Medicine: Cocreation of Ten Opportunities in Overuse and Underuse for Improving Value in Hospital Medicine. J Gen Intern Med 2018;33(6):804-806. https://doi.org/10.1007/s11606-018-4371-4.

41. Montano N, Costantino G, Casazza G, et al. The Italian Society of Internal Medicine choosing wisely campaign. Intern Emerg Med 2016;11(8):1125-1130. https://doi.org/10.1007/s11739-016-1560-1.

42. Livingston CJ, Freeman RJ, Mohammad A, et al. Choosing Wisely(R) in Preventive Medicine: The American College of Preventive Medicine's Top 5 List of Recommendations. Am J Prev Med 2016;51(1):141-149. https:// doi.org/10.1016/j.amepre.2016.03.009.

43. Bulger $\mathbf{J}$, Nickel $\mathbf{W}$, Messler $\mathbf{J}$, et al. Choosing wisely in adult hospital medicine: five opportunities for improved healthcare value. J Hosp Med 2013;8(9):486-492. https://doi.org/10.1002/jhm.2063.

44. McMahon LFJ, Beyth RJ, Burger A, et al. Enhancing patient-centered care: SGIM and choosing wisely. J Gen Intern Med 2014;29(3):432-433. https://doi.org/10.1007/s11606-013-2617-8.

45. Gupta S, Detsky AS. Development of choosing wisely recommendations for an inpatient internal medicine service. JAMA Intern Med 2015;175(4):642-644. https://doi.org/10.1001/jamainternmed.2014. 8119. 
46. ABIM Foundation. American Board of Internal Medicine. Choosing Wisely. http://www.choosingwisely.org. Accessed 25 Oct 2017.

47. Lee IT, Di Capua J, Cho HJ. Considering Cocreation for the Choosing Wisely List. Acad Med 2017;92(5):576. https://doi.org/10.1097/ACM. 0000000000001644 .

48. Levinson W, Born $\mathbf{K}$, Wolfson $\mathbf{D}$. Choosing Wisely Campaigns: A Work in Progress. JAMA. 2018;319(19):1975-1976. https://doi.org/10.1001/ jama.2018.2202

49. Shih T-H, Fan X. Comparing Response Rates from Web and Mail Surveys: A Meta-Analysis. Field Methods 2008;20(3):249-271. https:// doi.org/10.1177/1525822X08317085.

50. Blumenberg C, Barros AJD. Response rate differences between web and alternative data collection methods for public health research: a systematic review of the literature. Int J Public Health 2018;63(6):765773. https://doi.org/10.1007/s00038-018-1108-4.

51. Société Suisse de Médecine Interne Générale. Smarter Medicine Médecine Interne Générale. 2016.

52. Hasenfuss G, Marker-Hermann E, Hallek M, Folsch UR. [Choosing wisely in internal medicine]. Internist (Berl) 2016;57(6):521-526. https:// doi.org/10.1007/s00108-016-0062-6.

Publisher's Note Springer Nature remains neutral with regard to jurisdictional claims in published maps and institutional affiliations. 